\title{
Lithological heterogeneities in the mantle: origins and contributions to magma genesis
}

\author{
SARAH LAMBART \& OTTO LANG \\ Department of Geology and Geophysics, University of Utah, \\ Salt Lake City, UT-USA (sarah.lambart@utah.edu)
}

The quantification of mantle heterogeneity and its contributions to magma genesis are crucial for our understanding of the nature of Earth's geochemical reservoirs and recycling processes. Today, the source of basalts is often envisioned as a heterogeneous mantle that comprises a range of lithological heterogeneities, especially pyroxenites, introduced into the mantle by various geodynamic and magmatic processes.

Different chemical parameters have been proposed to trace evidence for the contribution of lithological heterogeneities during magma genesis (e.g., major elements ${ }^{1-}$ ${ }^{2}$, major element ratios ${ }^{1,3}$ or $\operatorname{logratios}^{4}$, first row transition element concentrations ${ }^{5-6}$, iron isotopes ${ }^{7}$ ) and several empirical models for partial melting of a heterogeneous mantle have been developed in an attempt to quantify the proportion of pyroxenites in the mantle source of magmas ${ }^{8-11}$. However, the large range of compositions covered by the potential lithologies present in the mantle makes it challenging to determine a unique proxy for their contributions in the magmas ${ }^{2,12}$. Additionally, these contributions are controlled by various factors, such as the abundances of the different lithologies in the mantle, their respective melting behaviors (solidus temperatures and melt productivities) and the thermal and melting regimes of the mantle. Finally, interpretations from the magma compositions are complicated by the potential presence of volatiles in the mantle source and/or by modifications experienced by the magmas during their journey through the mantle $e^{8,12}$.

This keynote presentation will present examples of challenges that can rise when we try to quantify the nature and abundance of the mantle heterogeneity, the efforts that have been published by various authors, and a few potential research directions that could bring prospects for success.

1- Hauri (1996), Nature 382, 2- Lambart et al. (2013), Lithos 160-161, 3- Hirschmann et al. (2003), Geology 31, 4- Yang et al. (2019), JGR-Solid Earth 124, 5- Sobolev et al (2007), Science 316, 6- Sobolev et al. (2008), Science 321, 7Williams and Bizimis, EPSL 404, 8- Mallik and Dasgupta (2014), GGG 15, 9- Kimura and Kawabata (2015), GGG 16, 10- Lambart et al. (2016), JGR-Solid Earth 121, 11- Brown and Lesher (2016), GGG 17, 12- Mallik et al. (in press), in: Konter J., Ballmer M, Cottaar S, \& Marquardt H. (Eds. ), AGU monograph. 